International Journal of Oceans and Oceanography

ISSN 0973-2667 Volume 14, Number 1 (2020), pp. 125-137

(C) Research India Publications

https://dx.doi.org/10.37622/IJOO/14.1.2020.125-137

\title{
Stepped Submerged Offshore Breakwaters for Wave Energy Dissipation
}

\author{
Sarhan, Th. E. \\ Associate Prof., Irrigation \& Hydraulics Dept., Faculty of Engineering, \\ EL-Mansoura University, El-Mansoura, Egypt
}

\begin{abstract}
An experimental study is conducted to develop stepped submerged offshore breakwaters as wave energy dissipater for shoreline protection. The erosion or accretion of shoreline along sandy beaches comes to be a big problem for sustainable development. Through this research, the author tries to find out a new shape of submerged breakwater to minimize the required area occupied by the breakwater, reduce the construction cost and improve the performance of the proposed new shape. The experimental work was adopted for significant cases of submergence ratio, structural and hydraulic parameters of stepped submerged breakwater. This is adopted under normal and regular waves with wide ranges of wave's heights and periods under constant water depth. The efficiency of the breakwaters is presented as a function of transmission and wave energy loss coefficients. The results represented that, the slotted stepped submerged breakwaters are more effective than without slotted ones in terms of reduction of transmitted waves in case of $\mathrm{B} / \mathrm{h}>1$, as well as $\mathrm{B} / \mathrm{L}>0.39$. Furthermore, Lower wave transmission and higher energy loss are obtained consistently at the lower submergence depth ratio.
\end{abstract}

Keywords: submerged breakwaters; stepped breakwaters; wave energy dissipater, perforated breakwaters; wave transmission coefficient; breakwater crest width; slotted breakwaters; submergence ratio

\section{INTRODUCTION}

In last few decades, submerged breakwaters have been increasingly used in coastal engineering works as wave protection and beach control device. Although their effectiveness is limited by the fact that they allow transmission into the shoreward 
region, the functional merited of crown submergence are often weightier to justify their adoption. As this type is commonly employed in coastal defense interventions, the prediction of the amount of energy transmitted behind it is a crucial point in design practice. This consideration led to a number of experimental studies aiming to derive practical design formula for wave transmission that is now commonly used in engineering practice. As a result of this, a considerable amount of data is now available and it's possible to perform a review and upgrading of the existing approaches.

The function of submerged breakwater on wave attack is not only the reduction of wave energy in shoreward of the structures, but also modification of spectral shape due to wave breaking on and wave energy dissipation in the structures. This covers an important role in the prediction of shoreline changes induced by structures. Also, this is in prediction of water wave reforming in case in which large fetches are present in lee of the structures, as pointed in Van der Meer et al. (2000). Many researchers have been investigated the performance of submerged breakwaters numerically and experimentally. Vertical, smooth, impervious structures was examined for wave transmission by using overtopping for wave transmission by Dick and Goda, Y., Takeda, and Moriya (1967). The breadth of the breakwater crest had disparity values; coefficients of wave reflection were estimated to determine the incident wave height affecting the structure. The penetrating and bottom standing vertical thick barriers were tested experimentally and theoretically by Mei and Black (1968), as well as using various of formulations as the basis for the numerical calibration of reflection and transmission coefficients and obtained precision within $1 \%$ for numerical findings.

Seeling (1980) obtained the most knowledge from hydraulic model experiments about wave transmission, reflection and energy dissipation. The measurements were generally limited to free surface oscillations on the land side and on the water side of submerged breakwater structures. The damping of impermeable underwater breakwater (thin, rectangular, trapezoidal and triangular) of varying forms was experimentally

Rai(1981).Mootaz Khaled (1992) has used submerged mound breakwater for studying wave energy dissipation.In order to determine the performance of breakwater AbulAzm (1993) measures the linear wave potential close to submerged thin barriers, using the Eigen Feature Extension.The experimental research by Isaacson et al. (1996) was undertaken to illustrate the event waves on a model of a single slice rubble-mound breakwater. Sarhan (1997), examined numerically the wave transformation passing submerged breakwaters and get relationship between the hydraulic and structural parameters for rubble mound breakwater. Heikal (1997) investigated experimentally and numerically with the Eigen feature expansion process the productivity of an impermeable, small, vertically submerged breakwater in sloping impermeable fields. The wave interaction with impermeable, submerged thick and thin breakwaters which were trapezoidal and rectangular, on horizontal and sloping beaches were experimentally and scientifically investigated by Koraem (2002). 
Dimitrios G. Stamos, et al. (2002), conducted wave tank experiments over a submerged hemi-cylindrical and rectangular rigid and water-filled flexible breakwater models. The results show that, for the rigid breakwaters, rectangular models are more effective than hemi-cylindrical ones in terms of reduction of transmitted waves. Stamos et al. (2003) have carried out an experimental parametric study to differentiate the features of reflection and transmission of submerged hemi-cylindrical and rectangular rigid in addition to water-filled flexible breakwater models. The dynamic interaction technique among water waves, a submerged breakwater, a sandy seabed and a vertical wall is experimentally examined. Jeng et al. (2005). The armor stone stability of the underwater reef and the impacts of the disparity distances from shore and crest breadth on ocean wave transmission has been tested experimentally by Shirlal et al. (2007). Musfique Ahmed and Rifat Anwar (2011) studied the effectiveness of the submerged breakwater as shore protection structures. Series of tests are carried out at a still water depth of $50 \mathrm{~cm}$ with a fixed rectangular submerged breakwater of three different heights $(30 \mathrm{~cm}, 35 \mathrm{~cm}$ and $40 \mathrm{~cm})$, for five different wave periods $(1.5 \mathrm{sec}, 1.6 \mathrm{sec}, 1.7 \mathrm{sec}, 1.8 \mathrm{sec}$, and $2.0 \mathrm{sec})$. Experiments' results showed the efficiency of submerged breakwater in decreasing the transmitted waves. A number of row-piles with different heights in experimental study were tested for shoreline protection by El-Saie Yasser Mohamed (2013). Hakeem K. Johnson et al. (2005) used an experimental data collected to validate two approaches for simulating waves and currents in the vicinity of submerged breakwaters. El Saie (2014), examined experimentally the effect of using submerged rectangular stepped breakwater for the defense of shoreline with the use of three variable height thin plates inside the wave tank. In the present work, results of an experimental study in wave flume at El-Mansoura University, Egypt are reported. Research focused on different aspects of interaction between waves and submerged stepped breakwaters, including amount of transmitted wave for with and without slots.

\section{EXPERIMENTAL SETUP}

The laboratory experiments were conducted at Irrigation and Hydraulics laboratory of faculty of engineering, El Mansoura University, Egypt. The models were tested in a $19 \mathrm{~m}$ long, $1.00 \mathrm{~m}$ wide and $1.00 \mathrm{~m}$ high wave flume. The wave generator is unidirectional wave flume equipped with a flap type wave generator. At the two ends of the flume, two wave absorbers were added to the flume so as to reduce the reflected waves in the flume, one with slope 7:1 at the end of the flume and the other as a basket filled with gravel.

The flume is made of three sectors; the first after the wave paddle is made of steel sides, the second is made of poly-carbonate sheets with $6 \mathrm{~mm}$ thickness and supported with steel angles, and the last part is made of steel plates. Fig. (1) shows the flume arrangements and dimensions. 


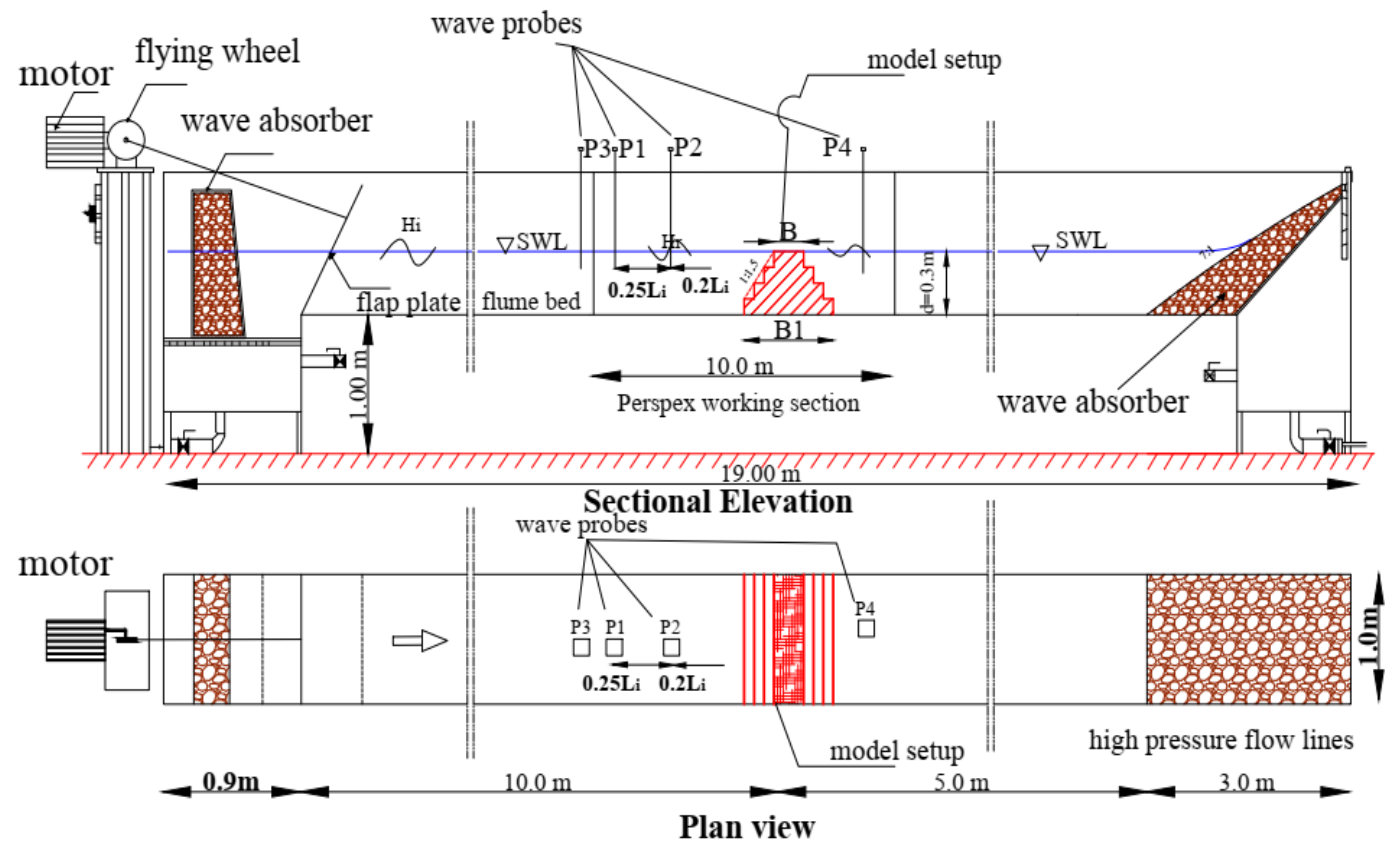

Fig. 1: Experimental Set-up for the Present Study

Fig. (2), illustrates the stepped breakwater model dimensions, Model1. Model (1), presents stepped submerged breakwater with $1.00 \mathrm{~m}$ width equal to the flume width and has crest width B and base width equal to B1. It has three steps, each one has 5 $\mathrm{cm}$ in width and $7.5 \mathrm{~cm}$ in height making slope equal to $1: 1.5(\mathrm{H}: \mathrm{V})$.

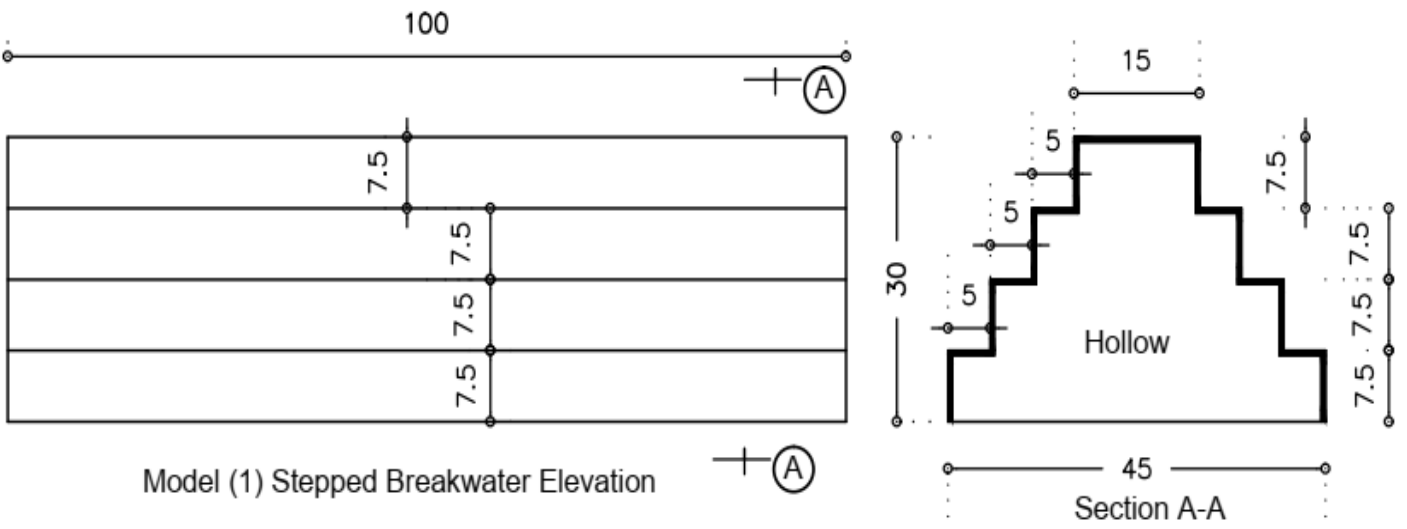

Fig. 2: Stepped Breakwater (Model No.1).

Fig. (3) shows the perforated stepped breakwater dimensions with perforation ratio equal to $13 \%$. The second model is similar to the first one with five slots, $5 \mathrm{~cm}$ diameter in each step as shown in the following figure; 

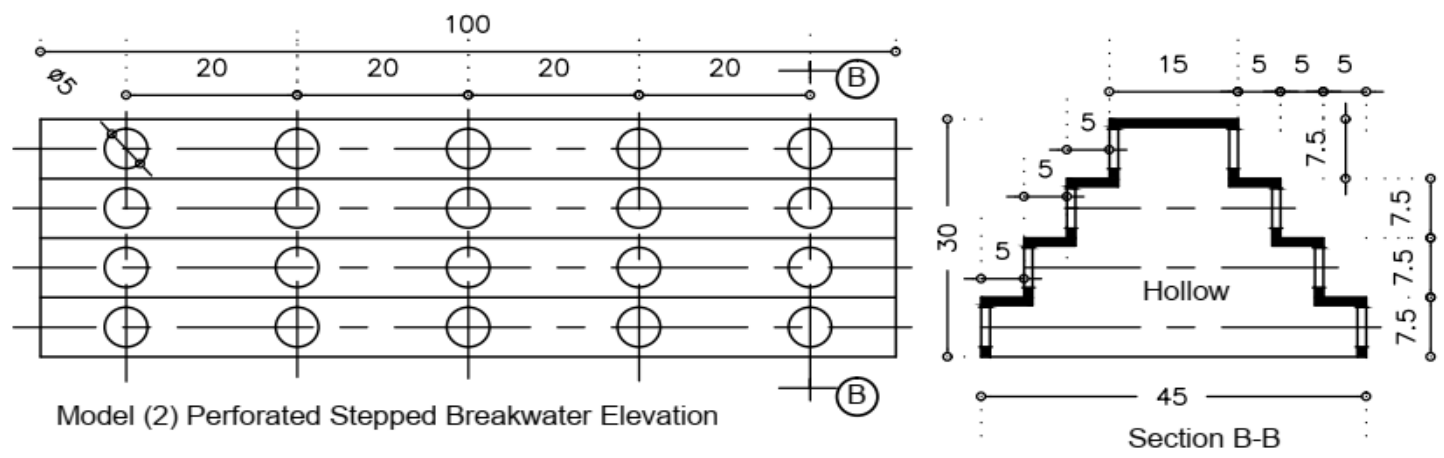

Fig. 3: Perforated Stepped Breakwater (Model No.2).

The most important structural and hydraulic variables with respect to wave transmission are summarized in this section and explained in Fig (4).

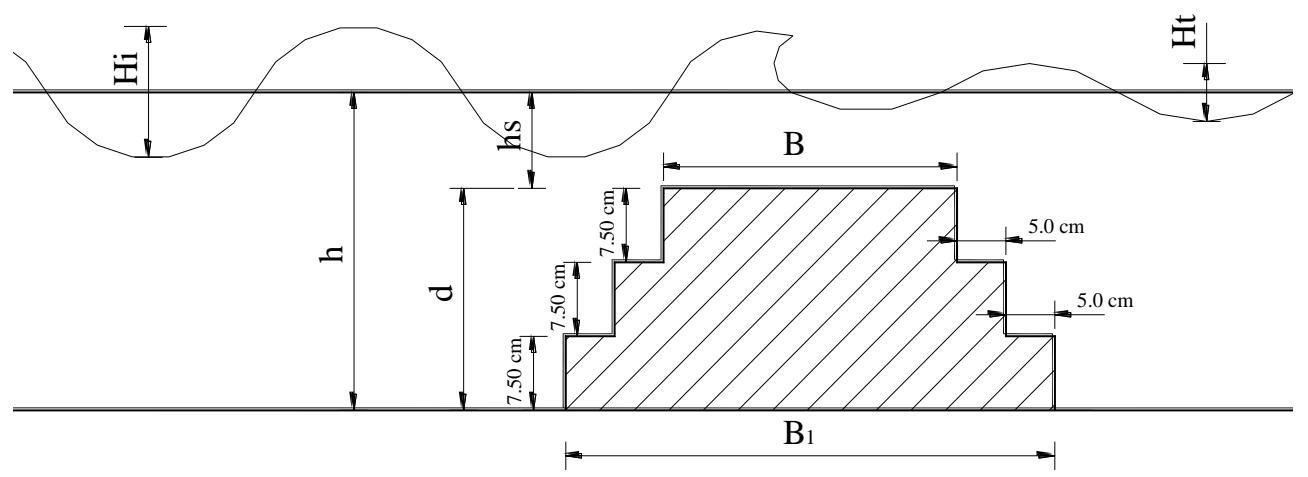

Fig. 4: Structural and hydraulic parameters definitions

As shown in previous studies, the transmission coefficient $\mathrm{K}_{\mathrm{t}}$ is defined as the ratio between the transmitted $(\mathrm{Ht})$ and the incident wave height $(\mathrm{Hi})$ and $\mathrm{Kt}=\mathrm{Ht} / \mathrm{Hi} . \mathrm{K}_{\mathrm{t}}$ values depend on the following structural parameters; $h_{s}$ is the water depth above the breakwater crest and measured from SWL., B is the breakwater crest width, $d$ is the breakwater height $=\mathrm{h}-\mathrm{hs}$. The ratio hs/h will be submergence ratio. As far as the hydraulic parameters are concerned, $\lambda$ is wave steepness $\left(\mathrm{H}_{\mathrm{i}} / \mathrm{L}\right)$ associated to the wave period $\mathrm{T}$, and $\mathrm{h}$ is the water depth. A wide database concerning experiments on wave transmission behind the model in the wave flume has been collected. The following parameters were derived;

Upper width of breakwater model, $\mathrm{B}=15,25$ and $35 \mathrm{~cm}$.

- $\quad$ Lower width of breakwater model, $\mathrm{B}_{1}=35,45$, and $55 \mathrm{~cm}$.

- $\quad$ Breakwater height, $\mathrm{d}=22.5,26.25$ and $30 \mathrm{~cm}$.

- $\quad$ Submergence ratio $=25 \%, 12.5 \%$ and $0.0 \%$. for each B

- $\quad$ Wave period, $\mathrm{T}=0.68,0.72,0.79,0.83,0.98$ and $1.05 \mathrm{sec}$. 
- $\quad$ Wave steepness, $\lambda=0.13,0.11,0.088,0.074,0.047$ and 0.035

The experimental work was divided into two groups, the first is breakwater without hole and second is perforated breakwater with 5 holes in each step its diameter $5 \mathrm{~cm}$ and perforation ratio is equal approximately to $13 \%$.

\section{RESULTS AND DISCUSSION}

A parametric study was carried out to investigate the hydrodynamic performance of stepped submerged hollow breakwater as a new measure to protect the shoreline erosion. The transmission coefficient, $\mathrm{Kt}$, is the ratio of the transmitted wave height to the incident wave height, this means that for lower values of $\mathrm{Kt}$ approve the stepped breakwater efficiency. $\mathrm{Kr}$ is the reflection coefficient, $\mathrm{Hr} / \mathrm{Hi}$. The dissipation of wave energy due to the impact on the breakwater is very complicated phenomena and very difficult to be measured with measurable devices. KL is the coefficient of dissipated energy $=1-\mathrm{kt}^{2}-\mathrm{kr}^{2}$. The performance of submerged stepped breakwater structures as a wave barrier depends on upon several parameters, the crest width, submergence ratio and the two models with or without slots were considered.

The processes of wave transmission in the presence of submerged stepped breakwater structure are accompanied by the loss of some portion of the incident wave energy; losses due to waves breaking over the breakwater, losses due to turbulence induced by crossing over and near the structure. The relationship between the characteristics of wave transmission and energy dissipation for the submerged stepped breakwater models can best be presented in terms of dimensionless parameters

$\mathrm{K}_{\mathrm{t}}=\frac{\mathrm{H}_{\mathrm{t}}}{\mathrm{H}_{\mathrm{i}}}, \lambda=\left(\frac{\mathrm{H}_{\mathrm{i}}}{\mathrm{L}}\right), \mathrm{kh}, \frac{\mathrm{h}_{\mathrm{s}}}{\mathrm{h}}, \frac{\mathrm{B}}{\mathrm{h}}, \frac{\mathrm{B}}{\mathrm{L}}$ where $\mathrm{k}=\frac{2 \pi}{\mathrm{L}}$ is the wave number. The coefficient of transmission $\mathrm{K}_{\mathrm{t}}$ is thus function of four variables;

$$
\mathrm{K}_{\mathrm{t}}=f\left(\mathrm{kh}, \lambda, \frac{\mathrm{h}_{\mathrm{s}}}{\mathrm{h}}, \frac{\mathrm{B}}{\mathrm{h}}, \frac{\mathrm{B}}{\mathrm{L}}\right)
$$

The analysis presented above was applied to several records for stepped breakwater with slots and stepped breakwater without slots models, under wave frequencies, and constant water depth, as presented above. In this section, we compare the effectiveness of two breakwaters models and present the transmission, and energy loss coefficients as a function of the parameters presented previously. First, we determine the effectiveness of the breakwater without slots and present the variations of the transmission, and energy loss coefficients with wave steepness $\lambda$ for three different submergence ratios $\frac{h_{s}}{h}$. Then, we perform the same comparison for the breakwater with slots. Finally, we provide an overall comparison of the effectiveness of breakwater with slots and without slots in terms of reduction of the transmission coefficient, $\mathrm{K}_{\mathrm{t}}$. 
The Fig. (5-A) includes three curves which show how the change in crest width of breakwater structure (B) with slots and without slots affects the wave transmission coefficient $\mathrm{K}_{\mathrm{t}}$ for various breakwater submerged ratio (hs/h).

In overall curves, the increase of (B) contributes in decreasing the wave transmission coefficient $\mathrm{K}_{\mathrm{t}}$ for two types of breakwater structure (slotted and without slots), however for a specific curve which $(\mathbf{h s} / \mathbf{h})=\mathbf{0 . 2 5}$, slotted structure and $\mathbf{B} / \mathbf{h}=\mathbf{0 . 8 3}$ the coefficient of transmission have slightly increased. At $\mathrm{B} / \mathrm{h}=0.5$ as well as, the increase of $\mathrm{B} / \mathrm{L}$, the wave transmission coefficient for both types of the structures are identical for $\mathrm{hs} / \mathrm{h}=0$ curve, however for $\mathrm{hs} / \mathrm{h}=0.125$ and $\mathrm{hs} / \mathrm{h}=0.25$, the $\mathrm{K}_{\mathrm{t}}$ for slotted breakwater is larger than without slots structures by $20 \%$ and $10 \%$ respectively.

At $\mathrm{B} / \mathrm{h}=0.83$ in addition to $\mathrm{B} / \mathrm{L}$ ratio increases, transmission coefficient for $\mathrm{hs} / \mathrm{h}=0$ curve is identical for both of structures. While for $\mathrm{hs} / \mathrm{h}=0.125$ and $\mathrm{hs} / \mathrm{h}=0.25$, the slotted breakwater structure is bigger than without slots breakwater structure by $10 \%$ and $40 \%$ for each.

But for $\mathrm{B} / \mathrm{h}>1$, the transmission coefficient for slotted structures remain larger than without slots breakwater structures until showing some fluctuation at $\mathrm{B} / \mathrm{L}$ approximately equal to 0.39 for each hs/h

As the increase of crest width (B) by $65 \%$, as well as $\mathrm{B} / \mathrm{h}<1$ the following variation have been noticed:

- For $\mathrm{hs} / \mathrm{h}=0$, the transmission coefficient of slotted and without slots breakwater structure have decreased approximately by $8 \%$, while for hs $/ \mathrm{h}=$ 0.125 , the $\mathrm{K}_{\mathrm{t}}$ reduced by $12 \%$ and $4.5 \%$ for slotted and without slots respectively. In contrary, the $\mathrm{hs} / \mathrm{h}=0.25$ curve shows the wave transmission coefficient goes up near to $5.5 \%$ for slotted breakwater structure but for without slots structures the $\mathrm{K}_{\mathrm{t}}$ has dropped by $20 \%$

- By the increase of the ratio $\mathrm{B} / \mathrm{L}$, the transmission coefficient remains steadily decreased

While the rise of crest width (B) by $135 \%$, as well as $\mathrm{B} / \mathrm{h}>1$ the following disparity have been recognized:

- For hs $/ \mathrm{h}=0, \mathrm{~K}_{\mathrm{t}}$ coefficient of slotted and without slots breakwater structure goes down by $64 \%$, whereas for $\mathrm{hs} / \mathrm{h}=0.125$, the $\mathrm{K}_{\mathrm{t}}$ dipped approximately by $30 \%$ and $20 \%$ for slotted and without slots respectively. In comparable with the $\mathrm{hs} / \mathrm{h}=0.25$, the wave transmission coefficient experienced decreased by $9.5 \%$ for slotted breakwater structure and $10 \%$ for without slots structures. 


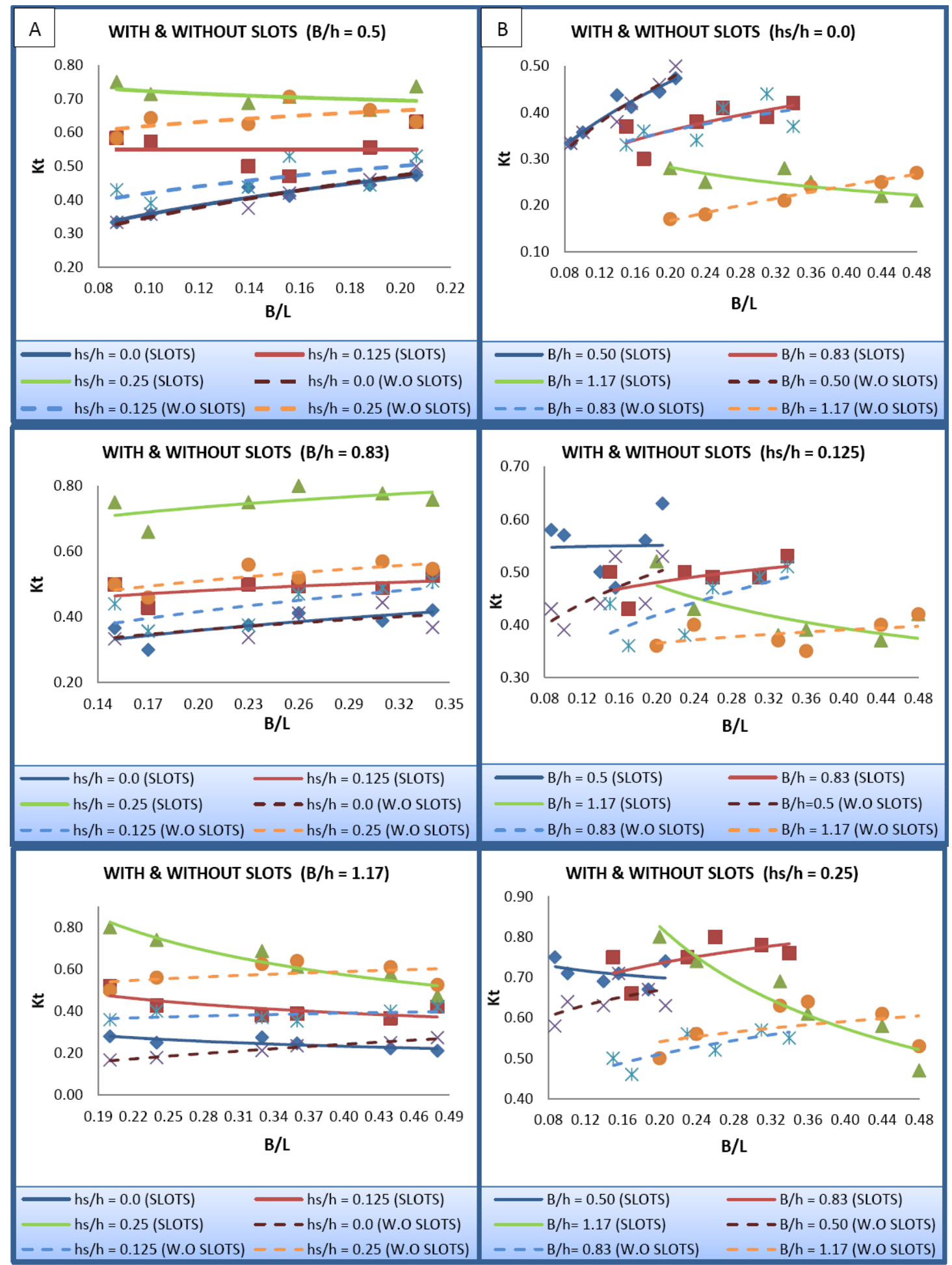

Fig. (5) (a): Transmission coefficient (Kt) for various crest width (B) of breakwater structure with slots \& without slots according to structure submerged ratio (hs/h) and $\mathrm{B} / \mathrm{L}$ ratio. (b): Transmission coefficient (Kt) for various breakwater submerged ratio (hs/h) with slots \& without slots according to structure crest width $(\mathrm{B})$ and $\mathrm{B} / \mathrm{L}$ ratio. 
By the increase of the ratio $\mathrm{B} / \mathrm{L}$, the transmission coefficient has a fluctuation for each hs/h for both structures. In other words, at a specific $\mathbf{B} / \mathbf{L}=\mathbf{0 . 3 9}$ in case of $\mathbf{B} / \mathbf{h}>\mathbf{1}$, the transmission coefficient for slotted structures level off and becomes less than without slots breakwater structures.

The Fig. (5-b) contains three curves which depicts the way which the variation in hs/h submerged ratio affects the wave transmission coefficient (Kt) for two types of breakwater structures (with slots and without slots structures)

In overall curves, the increase of submerged ratio triggers the wave transmission coefficient $(K t)$ for two types of breakwater structure (slotted and without slots) to go up rapidly.

As the increase hs/h by $12.50 \%$, the following results have been noticed:

- For $\mathrm{B} / \mathrm{h}=0.50$, the transmission coefficient of slotted and without slots breakwater structure have increased nearly by $34 \%$ and $12 \%$ respectively, while for $\mathrm{B} / \mathrm{h}=0.83$, the $\mathrm{K}_{\mathrm{t}}$ rise up by $30 \%$ and $15 \%$ for slotted and without slots respectively. Whereas the $\mathrm{B} / \mathrm{h}=1.17$ curve shows the wave transmission coefficient goes up by $70 \%$ for both types of structures

While the rise of hs/h by $25 \%$, the following influences have been recognized:

- For $\mathrm{B} / \mathrm{h}=0.50, \mathrm{~K}_{\mathrm{t}}$ coefficient of slotted and without slots breakwater structure increased by $70 \%$ and $55 \%$ for each, while for $\mathrm{B} / \mathrm{h}=0.83$, the $\mathrm{K}_{\mathrm{t}}$ grows up approximately by $35 \%$ and $40 \%$ for slotted and without slots respectively. However, for $\mathrm{B} / \mathrm{h}=1.17$, the wave transmission coefficient experienced rapidly increased by $160 \%$ for slotted breakwater structure and $160 \%$ for without slots structures.

- The previous detailed impacts are allocated in the following Figures (6-a) and (6-b):

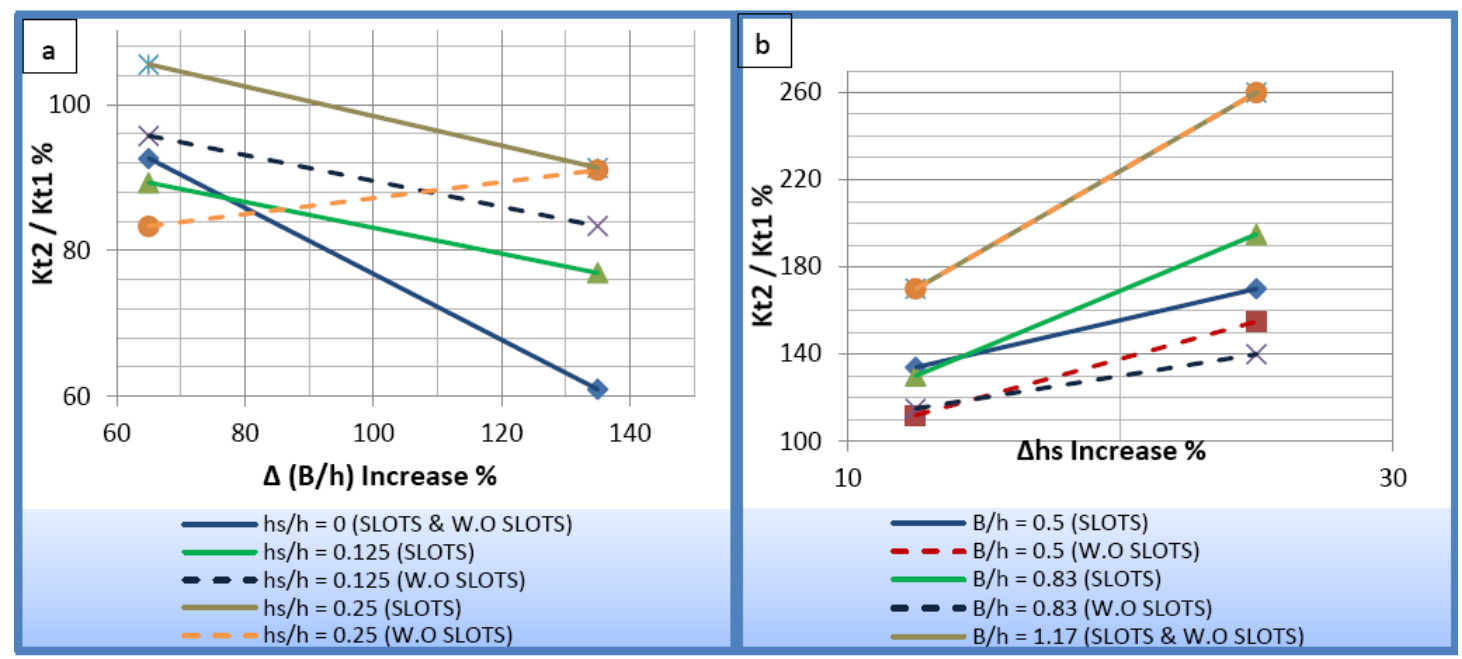

Fig (7- a) shows the variations of transmission coefficient, $K_{t}$, with wave steepness $(\lambda)$ for both models, for different cases of relative width $\mathrm{B} / \mathrm{h}=0.50, \mathrm{~B} / \mathrm{h}=0.83$ and $\mathrm{B} / \mathrm{h}=1.17$. The results show that for both models, the transmission coefficient, $\mathrm{K}_{\mathrm{t}}$, is 
decrease with increase relative width. While the effects of relative width for two models is very low for high values of submergence ratio $\mathrm{hs} / \mathrm{h}=0.25$.

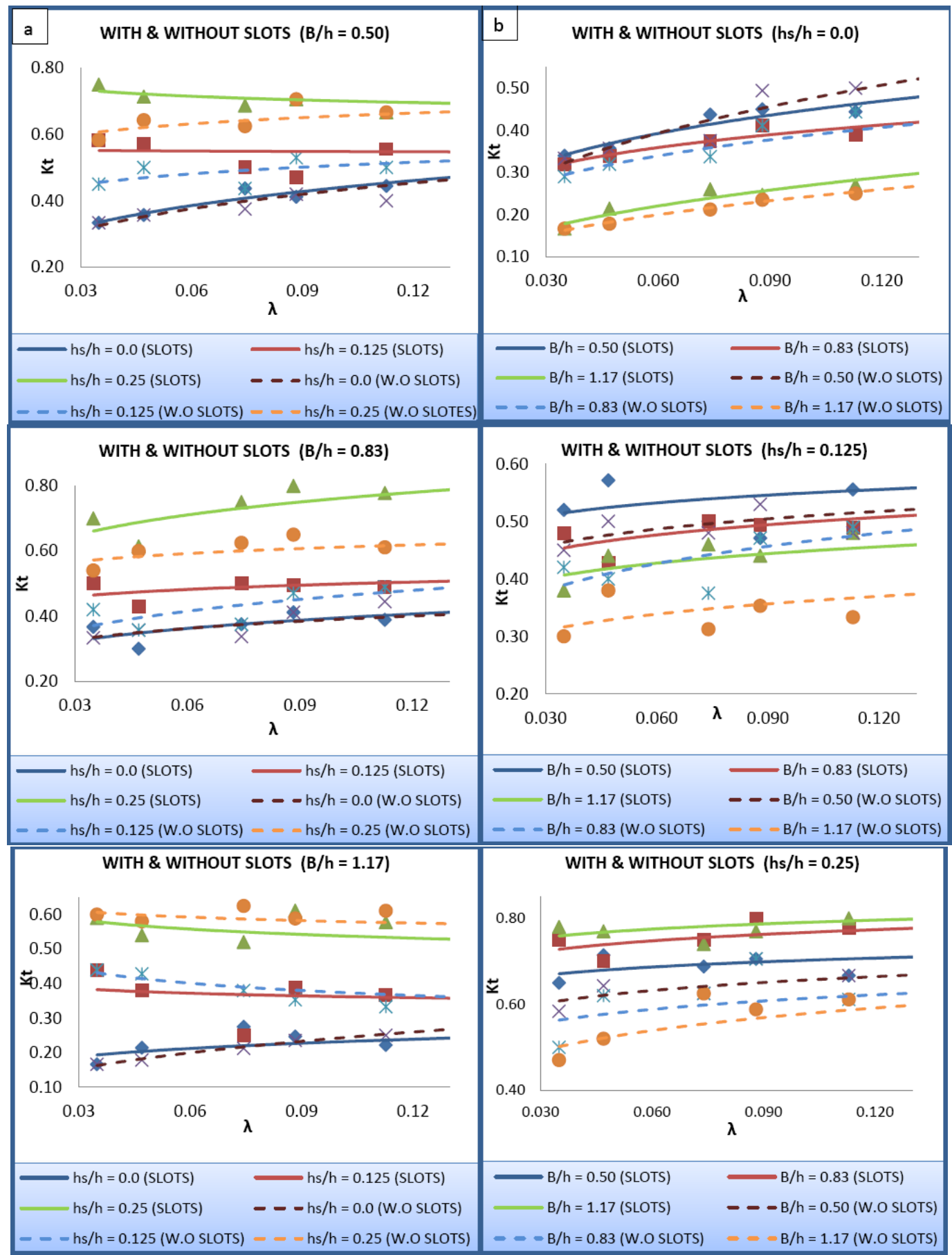

Fig. (7) (a): Transmission coefficient (Kt) for various crest width (B) of breakwater structure with slots \& without slots according to structure submerged ratio $(\mathrm{hs} / \mathrm{h})$ and wave steepness ratio $\underline{\lambda}$. (b) Transmission coefficient $(\mathrm{Kt})$ for various breakwater submerged ratio $(\mathrm{hs} / \mathrm{h})$ with slots \& without slots according to structure crest width (B) and and wave steepness ratio $\lambda$ 
By comparing Fig (5-a) and Fig (5-b), it's noted that the transmission coefficient, $\mathrm{K}_{\mathrm{t}}$, is, in general, larger in case of model with slots for high values of submergence ratio. But it remains the same for low submergence ratio, $h s / h=0$, which depict that the effects of slots are decreased by decreasing submergence ratio. In general transmission coefficient, $\mathrm{K}_{\mathrm{t}}$, is lower in case of higher relative width, $(\mathrm{B} / \mathrm{h})$, which show the highest efficiency of these structures in reducing wave height is a function of their crest width.

Fig (7-b) shows the variations of transmission coefficient, $K_{t}$, with wave steepness $(\lambda)$ for both submerged stepped breakwaters, with and without slots, for different cases of submergence ratio $h_{s} / h=0, h_{s} / h=0.125$ and $h_{s} / h=0.25$. The results show that for both models, the transmission coefficient, $\mathrm{K}_{\mathrm{t}}$, is increased with increase of submergence ratio. While these values approximately remain the same for two models for the high values of submergence ratio $h_{s} / h=0.25$. And by comparing Fig (5-a) and Fig (5-b), it's noted that the coefficient, $\mathrm{Kt}$, is, in general, larger in case of model with slots until showing a fluctuation at a specific value of $\mathrm{B} / \mathrm{L}$ ratio near to 0.39 . It's noted too, the transmission coefficient, $\mathrm{K}_{\mathrm{t}}$, is, in general, larger in case of higher submergence ratio, (hs/h). But on the other hand, the slotted structures is better than without slots breakwater structures for the rise of submergence ratio, in addition to the crest width over water depth is larger than unity, which clarify that the effectiveness of these structures in reducing wave height is a function of their levels under water level. Empirical relations were represented by analyzing experimental data; this technique is utilized to predict the effect of each parameter on the others. Statistical package for the social science (SPSS) program was used for analyzing the results. The dimensionless parameters are examined to estimate simple empirical relations to predict transmission coefficient for each model as shown below.

\begin{tabular}{|c|c|}
\hline$k t=o .36 \lambda^{-0.15}(B / h)^{-0.021}(1-h s / h)^{-2.64}$ & (With slots) \\
\hline$k t=o .005 \lambda^{0.08}(B / h)^{-0.21}(1-h s / h)^{-2.24}$ & (Without slots) \\
\hline
\end{tabular}

\section{CONCLUDING REMARKS:}

In this work, we performed a parametric experimental study to compare the transmission characteristics of submerged stepped breakwater without slots and submerged stepped breakwater with slots models. The study involves monochromatic waves propagating in the normal direction to the models, which are anchored to the bottom of a wave tank. Transmission coefficients are measured for a variety of wave conditions for models, as well as for different model width and diverse submergence ratio. 
The results depict that, for both models, the largest width models considered in this work are the most effective in the reduction of the transmitted wave height. On the other hand, the slotted breakwaters structures are more effective than without slotted ones in terms of reduction of transmitted waves only in case of crest width over water depth is larger than unity. For the influences of submergence ratio, it is noted that, for both models, the impacts arising from reducing the submergence ratio are significant in reduction of the transmitted wave height. Furthermore, the stepped slotted breakwater structure is better than the solid one in case no submergence ratio. Finally, for higher submergence ratio, slotted breakwater structures is the most preferable when the crest width is larger than water depth, in contrary for $\mathrm{B} / \mathrm{h}<1$, the breakwater without slots is more efficient.

\section{REFERENCES}

[1] Dimitrios G. S., Muhammad R. Hajj and Demetri P. Telionis, 2003 " Performance of Hemi-cylindrical and rectangular submerged breakwaters", Ocean Engineering 30, p. 813-828.

[2] El Saie Yasser Mohamed, 2014 " Effect of using submerged rectangular stepped breakwate for the defense of the shoreline", International Journal of Civil Engineering and Technology,Volume 5, Issue 2, pp.106-118.

[3] Eric C. CRUZ and Toshio AONO, 1998 "Wave and Current Fields Around Gapped Submerged Breakwaters", J. Hydrau., Coast. Environ. Eng., JSCE, No. 586/II-42, p. 127-135.

[4] Fernando J., and Miguel A., 2001 " Wave-Induced Mean Magnitudes in Permeable Submerged Breakwaters", Journal of Waterway, Port, Coastal, and Ocean Engineering, Vol. 127, No. 1, Paper No. 19011.

[5] H.M. The. and H Ismail, 2013 " Hydraulic Characteristics of a Stepped-slope Floating Breakwater", 4th International Conference on Energy and Environment, Series: Earth and Environmental Science 16, pp.1-4.

[6] Hakeem K. Johnson, Theophanis V. Karambas, Ioannis Avgeris, Barbara Zanuttigh, Daniel Gonzalez-Marco and I. Caceres, 2005, "Modelling of waves and currents around submerged breakwaters", Coastal Engineering 52, p. 949- 969 .

[7] Hanbin GU, Pengzhi LIN, Yanbao LI, Taiwen HSU and Jianlue HSU, 2003 "WAVE CHARACTERISTICS IN FRONT OF VERTICAL SEA-WALLS", International Conference on Estuaries and Coasts, Hangzhou, China.

[8] Isaacson M., 1991, "Measurement of Regular Wave Reflection", Journal of Waterway, Port, Coastal and Ocean Engineering, Vol. 117, No. 6, p. 553-569. 
[9] K. Al-Banaa and P. Liu, 2007, "Numerical Study on the Hydraulic Performance of Submerged Porous Breakwater under Solitary Wave Attack", Journal of Coastal Research, p. 201-205, Gold Coast, Australia, ISSN 0749.0208 .

[10] Lokesha, Kerpen.N.B., Sannasiraj.S.A., Sundar.V., Schlurmann.T., 2015 " Experimental Investigations on Wave Transmission at Submerged Breakwater with Smooth and Stepped Slopes", 8th International Conference on Asian and Pacific Coasts, Procedia Engineering 116, 713 - 719, Published by Elsevier Ltd.

[11] Mallayachari V. and Sundar V, 1996, "Wave Transmission over Submerged Obstacles in Finite Water Depths", Journal of Coastal Research, Vol. 12, No. 2, p. 477-483.

[12] Rey V., Belzons M. and Guazzelli E., 1992, "Propagation of Surface Gravity Waves Over a Rectangular Submerged Bar", Journal Fluid Mechanics, Vol. 235, p. 453-479.

[13] Sarhan, Th.E, $1997 "$ Transformation of Waves Passing Submerged Breakwaters", Mansoura Engineering Journal, Vol.30, No.3, pp. 1-11.

[14] Ty Wamsley, Hans Hanson and Nicholas C. Kraus, 2002, "Wave Transmission at Detached Breakwaters for Shoreline Response Modeling", ERDC/CHL CHETN-II-45

[15] Y.C. Guo, S.C. Mohapatra, C. Guedes Soares, 2020," Wave energy dissipation of a submerged horizontal flexible porous membrane under oblique wave interaction", Applied Ocean Research 94, 101948, pp. 1-16 
